\title{
Potenciais biomarcadores da terapia cognitivo-comportamental para o transtorno de estresse pós-traumático: uma revisão sistemática
}

\author{
Raquel Gonçalves 1,2 , Ana Cristina Lages ${ }^{1}$, Helga Rodrigues², Ana Lúcia Pedrozo ${ }^{1}$, Evandro Silva Freire Coutinho ${ }^{3}$, \\ Tom Neylan ${ }^{4}$, Ivan Figueira², Paula Ventura1,2
}

1 Institute of Psychology, Federal University of Rio de Janeiro (UFRJ), Rio de Janeiro, Brazil.

2 Institute of Psychology, UFRJ, Rio de Janeiro, Brazil.

${ }^{3}$ Department of Epidemiology, Escola Nacional de Saúde Pública (ENSP-Fiocruz), Brazil.

${ }_{4}^{4}$ Department of Psychiatry, University of California, Veterans Affairs Medical Center, San Francisco, USA.

Recebido: 1/9/2010 - Aceito: 27/12/2010

\begin{abstract}
Background: The establishment of biomarkers related to cognitive-behavior therapy (CBT) is a method to objectively consolidate treatment efficacy, which is critical to advancing the field. Objectives: We systematically reviewed studies that used biological parameters to assess the efficacy of CBT for the treatment of post-traumatic stress disorder (PTSD) and studies that used these parameters as predictors of response to CBT. Methods: Computerized literature searches were conducted in PubMed/Medline, ISI/Thompson Reuters, and Pilot databases using both thesaurus and free-word search terms. Results: 12 articles met the selection criteria; 4 of them were response predictors studies. A relationship was found between CBT efficacy and changes in the measured parameters, with heart rate responses to symptom provocation being the parameter most often studied. The reduction in heart rate was associated with an improvement in PTSD symptoms. The potential biomarkers of response predictions found included $5 \alpha$-reductase, amygdala activation, activation and volume of the anterior cingulate cortex, and heart rate. Discussion: Despite the scarcity of studies and their methodological shortcomings, initial investigations indicate that biomarkers of CBT in PTSD patients hold promise for more objective treatment outcome monitoring, identification of response predictors, and for developing novel treatment and prevention strategies.
\end{abstract}

Gonçalves R, et al. / Rev Psiq Clín. 2011;38(4):155-60

Keywords: Post-traumatic stress disorder, cognitive-behavioral therapy, biomarkers, systematic review.

\section{Resumo}

Contexto: $\mathrm{O}$ estabelecimento de biomarcadores relacionados à terapia cognitivo-comportamental (TCC) é uma maneira de consolidar a eficácia do tratamento de forma mais objetiva, sendo crítico para o avanço desse campo de pesquisa. Objetivos: Foi realizada uma revisão sistemática de estudos que: 1) utilizaram parâmetros biológicos para verificar a eficácia da TCC no tratamento do transtorno de estresse pós-traumático (TEPT); e 2) utilizaram esses parâmetros como preditores de resposta à TCC. Métodos: Foram conduzidas buscas eletrônicas nas bases PubMed/Medline, ISI/Thompson Reuters e Pilot. Resultados: Doze artigos foram selecionados para esta revisão, sendo quatro deles estudos sobre predição de resposta ao tratamento. Foi observada relação entre a eficácia da TCC e modificações nesses parâmetros, sendo a resposta da frequência cardíaca à evocação de sintomas o parâmetro mais utilizado até o presente momento. Sua redução está associada à melhora nos sintomas de TEPT. Potenciais biomarcadores de predição de resposta encontrados incluem $5 \alpha$-redutase, ativação da amígdala, ativação e volume do córtex cingulado anterior e freqüência cardíaca. Conclusão: Apesar da escassez de estudos e das limitações metodológicas neles observadas, investigações iniciais sugerem que os biomarcadores da TCC em pacientes com TEPT poderão ser úteis para o monitoramento mais objetivo dos efeitos do tratamento, identificação de predição de resposta e para o desenvolvimento de estratégias mais eficazes de tratamento e prevenção do desenvolvimento de TEPT.

Gonçalves R, et al. / Rev Psiq Clín. 2011;38(4):155-60

Palavras-chave: Transtorno de estresse pós-traumático, terapia cognitivo-comportamental, biomarcadores, revisão sistemática.

\section{Introduction}

The efficacy of cognitive-behavioral therapy (CBT) in the treatment of post-traumatic stress disorder (PTSD) is well documented ${ }^{1-5}$. CBT has been considered one of the treatment of choice for this disorder6. Psychometric measures (self-reported scales, in most cases) applied before and after treatment have been used as the basis for efficacy evaluation as quantitative indicators of symptom reduction. However, such methodology is not without limitations, as reporting biases can be problematic, particularly in the traumatology field. For example, Marmar ${ }^{7}$ pointed out that patients with PTSD may under-report symptoms to avoid the stigma attached to the disorder. Over-reporting of symptoms is also common as a way to obtain work-related disability benefits.

Some researchers have been searching for alternative ways to eliminate biases related to outcome evaluation. Therefore, in addition to psychometric tools, which are inherently vulnerable to the inaccuracies of subjects, researchers are making use of objective measures such as alterations in biological parameters related to therapy effects ${ }^{8}$. Those parameters have the potential for being more valid and reliable than the standard psychometric measures?

Another concern is related to the generalizability of psychotherapy study trials, which lack a placebo comparison condition. The development and use of valid biomarkers will increase the value of psychotherapy trials in which a credible attention control condition is not feasible?

Biomarkers may also be useful in treatment improvement. A considerable percentage of patients do not respond, or they drop out of treatment. In some studies, dropouts and no response rates can be as high as $50 \%{ }^{10}$. One possible approach to refining treatment is to examine which biological measures, for example, functional and structural brain imaging, neuroendocrine, and psychophysiological 
parameters, are changed by CBT in accordance with clinical improvement at the end of therapy. Theoretically, it may be possible to personalize treatment by enhancing interventions that have produced the greatest effects on a valid biomarker.

In addition, the identification of some key biomarkers could facilitate the prevention of the development of PTSD, as intervention programs specifically for at-risk individuals could be designed and implemented ${ }^{11}$.

The aim of this study was to perform a systematic review of the publications that have employed biological parameters to evaluate the effect of CBT in the treatment of PTSD and to investigate some biological predictors of treatment response. The present study pursued the hypothesis that CBT is able to change PTSD-related biological parameters.

\section{Methods}

\section{Study selection}

Several approaches were used to identify studies. First, we conducted an electronic search on August 19, 2009 in the following databases: ISI/Thompson Reuters, PubMed/Medline, and Pilot. In the ISI/ Thompson Reuters database, we restricted the search criteria to include only "articles" and "notes". In PubMed/Medline, PTSD and CBT terms were searched with the use of MeSH terms, whereas biological terms were searched directly in advanced search. Given that the studies found in the Pilot database are essentially trauma-related articles, keywords including PTSD were omitted. The results of each individual search were then combined.

To avoid the omission of articles that met the inclusion criteria, a manual search was conducted in addition to the electronic search on the list of references from selected articles and from the "time cited" list. Original articles, brief reports and letters published in languages other than English until the final search were considered for inclusion. Review articles, book chapters, theses and dissertations were excluded.

We next restricted the search criteria to include only studies conducted in humans with PTSD submitted to CBT techniques. Studies using techniques other than CBT were excluded. In addition, we included studies that investigated patients with co-morbid psychopathological conditions. Methodological limitations were also used as exclusion criteria. On that account, case reports, defined by Pincus et al. ${ }^{12}$ as a presentation of 10 cases or less, were excluded.

\section{Results}

Of the 308 articles that met the selection criteria of this systematic review, we excluded 30 articles that did not investigate PTSD or investigated partial PTSD, 77 that used techniques other than CBT techniques, 82 theoretical articles, thesis or dissertations, 16 studies that did not make use of biological parameters, 7 animal studies, 3 tool validation studies, 50 reviews and 22 case reports. Five articles were selected from reference lists. Therefore, the final analyses were based on 12 articles, 4 of which were response predictor articles. The articles are summarized in tables 1 and 2. In the end, a total of 333 patients were evaluated, and 187 patients were selected for experimental groups.

\section{Biological correlates of efficacy studies}

\section{Neuroendocrine studies}

One neuroendocrine study, performed by Smyth et al. ${ }^{13}$, was included in our analysis. The study was a randomized controlled trial, and the total number of patients in the experimental group was 15 . The authors measured cortisol levels only at three months after treatment. Although the authors did not find consistent symptom improvement, the experimental group had attenuated cortisol responses to trauma-related reminders compared to the control group.

\section{Psychophysiological studies}

We identified seven studies involving psychophysiological parameters. Two of these studies used electromyography to measure the efficacy of therapy, one of which was a randomized controlled trial ${ }^{14}$, while the other was a non-controlled trial ${ }^{15}$. By summing up the number of participants submitted to CBT in both studies, there were a total of 39 subjects (all war veterans). Both studies used flooding as a CBT technique, and the participants were submitted to facial electromyography, heart rate monitoring and skin conductance (SC) during the sessions. Boudewyns and Hyer ${ }^{14}$ reported that the decrease in EMG was not statistically related to the decrease in psychometric measures. Similarly, Pitman et al. ${ }^{15}$ did not find a statistical relationship between EMG decrease and decrease in psychometric measures.

With respect to SC, three studies, including the two cited above, used SC to measure the efficacy of CBT ${ }^{16}$. Considered together, the number of participants in the experimental group was 64 . The decrease in SC response to trauma reminders was statistically related to the decrease in psychometric measures, with no statistical difference between the two interventions. There was, however, a more pronounced decrease in reactivity in the experimental group compared to controls. The experimental group showed decreased reactivity to two of three repeats of the audiotape, whereas the control group showed a decrease only for one playing ${ }^{14}$. The reduced $\mathrm{SC}$ response was found to be a trend in another article ${ }^{15}$, and, in the third study ${ }^{16}$, there were no significant differences in SC response in the treatment group. Moreover, this latter study did not detail their SC results.

Seven studies used heart rate to index the efficacy of CBT, four of which were controlled trials. In total, 84 patients were submitted to CBT. We observed a relationship between heart rate reduction and CBT response in six of the seven selected studies. There was a statistically significant decrease in heart rate responses to trauma reminders in the active treatment groups versus the control groups in the three studies ${ }^{15-17}$ and a trend for a decrease in another three articles ${ }^{14,18,19}$. All of these studies used the symptom provocation paradigm. The only study that did not find this relationship was an article that only employed a resting method ${ }^{20}$.

Blood pressure was used by two studies, both of which were randomized controlled trials. A total of 37 subjects were submitted to CBT in these studies combined. In one of the studies, there were no changes in blood pressure after therapy ${ }^{16}$, whereas the other study reported a significant decrease in systolic pressure ${ }^{20}$.

\section{Neuroimaging studies}

We identified one non-controlled fMRI study of 13 subjects, which showed a match between a positive result of CBT and activation of brain areas involved in social cognition (left medial temporal gyrus, which is considered to be related to empathy, posterior cingulate gyrus, medial frontal gyrus, and left medial superior temporal gyrus, which are associated with forgiveness). The association of the areas with empathy and forgiveness was previously identified by the authors ${ }^{21}$ in a paradigm in which 10 volunteers were asked to make judgments based on social scenarios. The left superior frontal gyrus, orbitofrontal gyrus and precuneus were activated by judgments of empathy. In the study conducted by Farrow et al.21, the subjects were engaged in tasks that involved speculation on another's intention as well as making judgments of the forgiveness of the actions of others before and after therapy, in addition to invoking empathy. The CBT in their study included a forgiveness component.

\section{Biological correlates of response prediction}

Four trials that investigated the prediction of CBT response through biological parameters measured during pretreatment were found. The parameters assessed by these studies were found to be good 
response predictors. CBT non-responders $(\mathrm{N}=14)$ were found to have $5 a$-reductase (a cortisol metabolite) levels that were $70 \%$ lower than those of responders $(\mathrm{N}=14)^{22}$. Another study showed that CBT non-responders had greater bilateral amygdala and ventral right anterior cingulate cortex activation during the presentation of fearful and neutral facial expressions ${ }^{23}$ compared to CBT responders. Further, CBT responders had greater anterior cingulate cortex volume at pretreatment ${ }^{24}$. Increased heart rate during pretreatment predicted a favorable outcome following $\mathrm{CBT}^{15}$. Cortisol and some of its metabolites, however, were not found to be good predictors of CBT response ${ }^{22}$.

\section{Discussion}

To the best of our knowledge, there have been no systematic reviews evaluating changes in biological markers as a result of CBT treatment in PTSD patients or whether these markers predict treatment response.

A trend toward an increase in the number of treatment studies with biological measures was observed. From 1985 to 1990, only two studies could be identified, and from 1991 to 1995 , there were no studies identified. In contrast, from 1996 to 2000, three publications met our criteria, and even more studies were identified after 2005 (five studies from 2006-2009).

Table 1. Selected studies

\begin{tabular}{|c|c|c|c|c|c|}
\hline Study & Design & Procedure & Biological measures & CBT efficacy & Biological changes \\
\hline Smyth et al.13, 2008 & $\begin{array}{l}\text { Randomized. Placebo } \\
(\mathrm{n}=10) \text { or expressive } \\
\text { writing }(\mathrm{n}=15) \text {. } \\
\text { Total: } n=25\end{array}$ & $\begin{array}{l}3 \text { sessions of expressive } \\
\text { writing ( } 20^{\prime} \text { each with } 15^{\prime} \\
\text { interval - all performed in } 1 \\
\text { day). Cortisol assessed only } \\
\text { during Follow-up }\end{array}$ & $\begin{array}{l}\text { Cortisol (saliva } \\
\text { samples) }\end{array}$ & $\begin{array}{l}\text { No changes in PTSD } \\
\text { symptoms. Improvements } \\
\text { in mood. }\end{array}$ & $\begin{array}{l}\text { Attenuation of cortisol } \\
\text { responses to trauma-related } \\
\text { memories in experimental } \\
\text { group* at post-treatment } \\
\text { and greater recovery after } \\
20 \text { min of rest }\end{array}$ \\
\hline $\begin{array}{l}\text { Boudewyns and } \\
\text { Hyer }^{14}, 1990\end{array}$ & $\begin{array}{l}\text { Randomized. Flooding } \\
\text { ( } n=19) \text { or counseling } \\
(n=19) . \\
\text { Total: } n=38\end{array}$ & $\begin{array}{l}\text { 10-12 weekly sessions of } 50 \\
\text { min each }\end{array}$ & $\begin{array}{l}\text { Frontal EMG, heart } \\
\text { rate, skin conductance }\end{array}$ & $\begin{array}{l}\text { Flooding group showed } \\
\text { improvement in symptoms } \\
\text { compared to controls in } \\
\text { VET* }^{*}\end{array}$ & 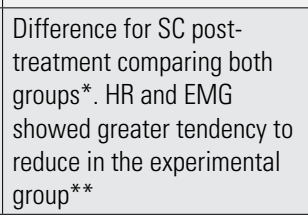 \\
\hline Pitman et al.15, 1996 & Not controlled. $\mathrm{n}=20$ & 12 weeks of flooding/relaxation & \begin{tabular}{|l|} 
HR, SC, left lateral \\
frontalis EMG and left \\
corrugator EMG
\end{tabular} & $\begin{array}{l}\text { Improvement in avoidance } \\
\text { symptoms and intrusions* } \\
\text { and improvement in other } \\
\text { symptoms** }\end{array}$ & $\begin{array}{l}\text { Reduction of all variables, } \\
\text { but only heart rate showed } \\
\text { reduction* }\end{array}$ \\
\hline $\begin{array}{l}\text { Blanchard et al.16, } \\
2002\end{array}$ & $\begin{array}{l}\text { Randomized. CBT }(n=25) \text {, } \\
\text { counseling therapy }(n=26) \\
\text { and wait list ( } n=22) \text {. } \\
\text { Total: } n=73\end{array}$ & $\begin{array}{l}\text { 8-12 sessions of writing, in vivo } \\
\text { exposure, relaxation, cognitive } \\
\text { techniques }\end{array}$ & $\begin{array}{l}\text { Skin conductance, } \\
\text { blood pressure and } \\
\text { heart rate }\end{array}$ & $\begin{array}{l}\text { CAPS reduction in CBT } \\
\text { group* }\end{array}$ & $\begin{array}{l}\text { Heart rate decrease in the } \\
\text { CBT group* }\end{array}$ \\
\hline Frueh et al.17, 1996 & Not controlled. $n=11$ & $\begin{array}{l}29 \text { sessions during } 17 \text { weeks of } \\
\text { Trauma Management Therapy } \\
\text { (exposure, psychoeducation, } \\
\text { SST and programmed practice) }\end{array}$ & Heart rate & $\begin{array}{l}\text { Treatment effects in } \\
\text { CGI, HAMA, increasing } \\
\text { hours of sleep and social } \\
\text { activities* and CAPS } \\
\text { (trend) }\end{array}$ & $\begin{array}{l}\text { Heart rate reactivity } \\
\text { decreased in post-treatment } \\
\text { relative to pretreatment* }\end{array}$ \\
\hline $\begin{array}{l}\text { Cooper and Clum }{ }^{18} \text {, } \\
1989\end{array}$ & Not randomized. $n=14$ & $\begin{array}{l}\text { 6-14 sessions of } 90 \mathrm{~min} \text {, each } \\
\text { (once or twice a week) of } \\
\text { flooding/relaxation }\end{array}$ & Heart rate & $\begin{array}{l}\text { Reduction of revival and } \\
\text { sleep disturbance, mainly. } \\
\text { Reduction of STAI and BDI }\end{array}$ & $\begin{array}{l}\text { Heart rate did not } \\
\text { show reduction in the } \\
\text { experimental group, but } \\
\text { increased in the control } \\
\text { group }{ }^{* *}\end{array}$ \\
\hline $\begin{array}{l}\text { Fecteau and Nicki19, } \\
1999\end{array}$ & $\begin{array}{l}\text { Randomized. CBT }(n=10) \\
\text { or wait list }(n=10) \text {. Total: } \\
n=20\end{array}$ & $\begin{array}{l}\text { 8-10 sessions of } \\
\text { psychoeducation, relaxation, } \\
\text { exposure, restructuring and } \\
\text { self-instruction }\end{array}$ & Heart rate & $\begin{array}{l}\text { Treatment effects across } \\
\text { structured interviews, } \\
\text { self-report questionnaires } \\
\text { and the behavioral test in } \\
\text { the CBT group* }\end{array}$ & $\begin{array}{l}\text { Greater reactivity decreased } \\
\text { in the CBT group** }\end{array}$ \\
\hline Hinton et al.20, 2009 & $\begin{array}{l}\text { Randomized. CBT }(n=12) \\
\text { or wait list }(n=12) \text {. Total: } \\
n=24\end{array}$ & $\begin{array}{l}12 \text { weeks of cognitive } \\
\text { restructuring, diaphragmatic } \\
\text { breathing, muscle relaxation, } \\
\text { psychoeducation, guided } \\
\text { image, interoceptive exposure }\end{array}$ & $\begin{array}{l}\text { Systolic blood } \\
\text { pressure, diastolic } \\
\text { blood pressure, heart } \\
\text { rate }\end{array}$ & $\begin{array}{l}\text { Greater improvement in } \\
\text { CBT group than wait list. } \\
\text { Regulation of emotion } \\
\text { and panic }\end{array}$ & $\begin{array}{l}\text { Diastolic blood pressure and } \\
\mathrm{HR}^{* *} \text {. Reduction in systolic } \\
\text { blood pressure*} \text {, which } \\
\text { was highly correlated with } \\
\text { improvement in regulation of } \\
\text { negative affective states }\end{array}$ \\
\hline Farrow et al.21, 2005 & Not controlled. $n=13$ & $\begin{array}{l}\text { 4-10 sessions of CBT including } \\
\text { forgiveness component. Did not } \\
\text { specify employed techniques }\end{array}$ & fMRI (brain areas) & $\begin{array}{l}\text { Reduction in CAPS after } \\
\text { treatment*. Tendency to } \\
\text { reduction at IRI and EFI** }\end{array}$ & $\begin{array}{l}\text { Increase in activation of } \\
\text { brain areas involved in } \\
\text { social cognition (left medial } \\
\text { temporal gyrus, related to } \\
\text { empathy; posterior cingulate } \\
\text { gyrus, medial frontal gyrus, } \\
\text { and left medial superior } \\
\text { temporal gyrus, associated } \\
\text { with forgiveness) }\end{array}$ \\
\hline
\end{tabular}

*: statistically significant; ** not statistically significant; VET: Veterans Adjustment Scale; CGI: Clinical Global Impression; HAMA: Hamilton Anxiety Scale; CAPS: Clinician-Administered PTSD Scale; BDI: Beck Depression Inventory; SPAI: Social Phobia and Anxiety Inventory; AX: Spielberger Anger Expression Inventory; STAl: Spielberger State-Trait Anxiety Inventory; IRI: Interpersonal Reactivity Index; EFI: Enright Forgiveness Inventory; SST: Social Skills Training; HR: heart rate; SC: skin conductance. 
Table 2. Response prediction studies

\begin{tabular}{|c|c|c|c|c|c|}
\hline Study & Design & CBT protocol & Procedures & Biological measures & Results \\
\hline $\begin{array}{l}\text { Pitman et al.15, } \\
1996\end{array}$ & Not controlled. $n=20$ & $\begin{array}{l}12 \text { weeks of flooding and } \\
\text { relaxation }\end{array}$ & $\begin{array}{l}\text { Monitoring during the first } \\
\text { and last series of flooding } \\
\text { sessions }\end{array}$ & $\begin{array}{l}\text { Heart rate, skin } \\
\text { conductance, EMG }\end{array}$ & $\begin{array}{l}\text { Increased heart rate before } \\
\text { treatment was associated } \\
\text { with better therapeutic } \\
\text { response (reduction of } \\
\text { intrusive thoughts) }\end{array}$ \\
\hline $\begin{array}{l}\text { Yehuda et al.22, } \\
2009\end{array}$ & $\begin{array}{l}\text { Randomized. Prolonged } \\
\text { exposure }(n=14) \text { or } \\
\text { orientation }(n=14) \text {. } \\
\text { Total: } n=28\end{array}$ & Not specified & $\begin{array}{l}\text { Collected over } 24 \text { hours } \\
\text { through urine before and } \\
\text { after treatment and at } 3 \\
\text { month follow-up. Baseline } \\
\text { measurement }\end{array}$ & Cortisol and metabolites & $\begin{array}{l}5 \alpha \text {-reductase (derived } \\
\text { from the metabolite and } \\
\text { glucocorticoid measures) } \\
\text { was } 70 \% \text { decreased in } \\
\text { pretreatment in non- } \\
\text { respondents. No other } \\
\text { hormone was a predictor }\end{array}$ \\
\hline $\begin{array}{l}\text { Bryant et al.23, } \\
2008\end{array}$ & $\begin{array}{l}\text { Not controlled. Diagnosed } \\
\text { with PTSD: } n=14 \text {. } \\
\text { Total: } n=28\end{array}$ & $\begin{array}{l}8 \text { weekly sessions of } \\
\text { psychoeducation, imaginal } \\
\text { exposure, cognitive re- } \\
\text { structuring and relapse } \\
\text { prevention }\end{array}$ & $\begin{array}{l}\text { Scanning before treatment } \\
\text { and while viewing images } \\
\text { of four men and four } \\
\text { women expressing fear and } \\
\text { alternating with neutral } \\
\text { expressions }\end{array}$ & Brain areas (fMRI) & $\begin{array}{l}\text { Non responders had greater } \\
\text { activation of bilateral } \\
\text { amygdala and right ventral } \\
\text { anterior cingulate cortex } \\
\text { during the presentation of the } \\
\text { stimuli before treatment }\end{array}$ \\
\hline $\begin{array}{l}\text { Bryant et al. }{ }^{24}, \\
2008\end{array}$ & $\begin{array}{l}\text { PTSD: } n=13 \text {. History of } \\
\text { trauma and no PTSD: } \\
n=13 . \text { Without history of } \\
\text { trauma: } n=13 \text {. } \\
\text { Total: } n=39\end{array}$ & $\begin{array}{l}8 \text { weekly sessions of } \\
\text { psychoeducation, imaginal } \\
\text { exposure, cognitive re- } \\
\text { structuring and relapse } \\
\text { prevention }\end{array}$ & $\begin{array}{l}\text { Scanning before and after } \\
\text { treatment } \\
\text { (volume measurement) }\end{array}$ & $\begin{array}{l}\text { Brain areas (structural } \\
\text { magnetic resonance } \\
\text { imaging - MRI) }\end{array}$ & $\begin{array}{l}\text { Responders had higher } \\
\text { rostral anterior cingulate } \\
\text { cortex volume comparing to } \\
\text { non-responders }\end{array}$ \\
\hline
\end{tabular}

\section{Biological correlates of efficacy studies}

In general, research results from the present systematic review supported the hypothesis that CBT can change biological parameters. The majority of studies observed some evidence of change in biological parameters in association with treatment response as evaluated through symptom scales.

Concerning heart rate, most of the studies found a correlation between CBT response and a reduction of cardiac reactivity to trauma scripts. At present, this parameter is the most promising biomarker of CBT efficacy because of the association with treatment response and the relatively large number of studies that have used this parameter in comparison with the other parameters. The common use of heart rate is likely associated with its easy implementation and its sensitivity to trauma cues. Indeed, heart rate reactivity has been considered one of the most promising biological correlates of PTSD ${ }^{25,26}$.

EMG and blood pressure did not appear to be potential indicators of CBT efficacy. In the two studies that met our criteria for inclusion, EMG and blood pressure measures did not parallel the changes in the scores of scales administered before and after treatment, with exception of systolic blood pressure in one of the studies. The replication of these data should be necessary for more consistent conclusions.

Cortisol reactivity to trauma script also did not appear to be associated with CBT response. Nonetheless, subjects who had received sessions of expressive writing for PTSD showed less reactivity in cortisol levels to trauma scripts, suggesting that successful treatment is associated with improvement in the capacity to regulate stress responses. This study, however, involved only three sessions of expressive writing, which is considered insufficient to produce therapeutic effects 2 . It is also important to note that the above mentioned study did not inform if PTSD participants had concurrent co-morbid diagnoses, as depression, a common co-morbid condition in PTSD, is expected to be associated with increased cortisol levels ${ }^{27}$, which might be a confounding issue. SC tests showed inconsistent results, as it was associated with CBT response in only one of the three studies in which it was measured. Given that the number of studies found was limited, however, more publications are needed to produce more consistent results.

Successful treatment with CBT was associated with increased activation of neural areas involved in social cognition (left medial temporal gyrus, which is related to empathy; posterior cingulate gyrus, medial frontal gyrus, and left medial superior temporal gyrus, which are associated with forgiveness). It is interesting to note that despite being one of the most promising techniques, functional imaging has been underutilized in PTSD treatment studies ${ }^{28}$. In contrast, there have been more fMRI studies in treatment studies involving patients with obsessive-compulsive disorder, specific phobias and panic disorder ${ }^{28}$. More investigations with PTSD patients are needed to test whether treatment response is associated with similar patterns of brain activation, as found in other anxiety disorders.

\section{Biological correlates of response prediction}

Despite the limited number of studies found, there is a suggestion that some biological parameters have a potential clinical utility in predicting CBT response, namely the enzyme 5a-reductase, amygdala activation, anterior cingulate cortex activation and volume and heart rate. Exceptions were cortisol and some of its metabolites. Yehuda et al. ${ }^{29}$ found significantly lower $5 \alpha$-reductase activity in Holocaust survivors and suggested that its reduction may be associated with a vulnerability to development of PTSD. The highest amygdala activation in non-responders and highest anterior cingulate cortex volume in responders before treatment are compatible with the current model of PTSD ${ }^{30,31}$, which is based in neuroimaging data that show exaggerated amygdala activation and decreased activation in frontal areas. Despite data demonstrating that amygdala activation during exposure treatment is required for the extinction process to occur, depending on PTSD severity, the excessive activation is harmful to fear processing, perhaps because it might be harder to regulate the anxiety elicited by $\mathrm{CBT}^{23}$. The highest activation of the anterior cingulate cortex could be associated with the rapid presentations of the fear stimuli in a backwards masking paradigm, predominantly engaging subcortical networks. Finally, the highest heart rate reactivity in responders could be explained by a greater engagement with trauma-related cues in those participants.

The study conducted by Hinton et al. ${ }^{20}$ was the only study that did not make use of idiographic symptom provocation as a method to measure a biological parameter. All of the other publications used idiographic symptom provocation, which allows for a better comparison between selected articles. The comparison of data from these studies is limited by the great variability in the time of data 
collection. For example, some studies used the first or last minutes of symptom provocation or minutes with peak response.

\section{Methodological limitations of the reviewed studies}

Several design limitations were found in the papers included in our analysis. Small sample sizes, with 7 of 10 studies using a sample smaller than 30 (not including response predictor studies) was the first and most prominent limitation. The fact that the majority of these studies were underpowered might explain the lack of statistical significance in some parameters in relation to CBT outcome. Indeed, several of these studies reported a non-significant trend among their main results. Additional problems included the absence of information about the use of psychotropic medication in three studies and the use of non-stabilized psychotropic medication in four studies. One paper allowed participants who were enrolled in other psychotherapy to keep the original treatment and enter the study ${ }^{15}$. Five studies did not describe the presence of co-morbid conditions, and one study stated that there was a co-morbid condition, but the authors failed to mention the coexisting disorder. Conversely, six studies described co-morbid conditions that included mostly major depression. The absence of controlling for co-morbid disorders is relevant because biological parameters may be differentially altered according to the different co-morbid diagnosis, which may have led to confounding results. The decision to include studies containing a control group and not containing a control group was due to the few trials found through our searches. The possibility of placebo effects in non-controlled trials, however, should be considered, as it may invalidate some of the data identified.

As an emerging field, such data should be interpreted with caution. The use of different methods and evaluation tools makes it difficult to generalize the results. It should also be noted that this review was restricted to the evaluation of results in published papers and covered only peer-reviewed literature, which may have omitted studies that could have met our inclusion criteria.

\section{Potential clinical implications}

Despite the major advances in neuroscience and biological fields over the last decade, few behavioral treatment studies in psychological literature have examined the effects of therapy on the body'1. As noted by Beauchaine et al. ${ }^{11}$, "such use of biological markers in longitudinal outcome research represents a first step toward a more integrated prevention science" (p. 747). Notwithstanding the consolidated efficacy of CBT, there are patients who do not respond to the intervention and continue to present significant psychological suffering at the end of therapy ${ }^{32}$. Therefore, the development of studies in the basic area that allow the improvement of therapy is necessary and will allow for better treatments to be developed for patients who fail to respond to currently available therapies. The study of biological variables in the course of psychological treatment has the potential to accelerate innovation in the development of more effective treatments. This progress can occur by the development of more effective interventions and prevention of specific pathologies deriving from laboratory knowledge. Knowledge from basic research can then be transposed to applied research, amplifying therapeutic possibilities and treatment outcomes.

\section{Conclusion}

The current systematic review showed that, despite the scarcity of studies for this purpose in the literature, there is a relationship between the efficacy of CBT and changes to biological parameters in PTSD patients. At our current state of technology, however, the superiority of biological markers over traditional methods is not established. In the future, biological variables may prove to be useful tools in expedite the development of more individualized and effective treatments.

\section{Acknowledgements}

This work was supported by CNPq (National Counsel of Technological and Scientific Development) - Federal Government of Brazil, Faperj (Fundação de Amparo à Pesquisa do Estado do Rio de Janeiro) - Programa de Apoio às Instituições de Ensino e Pesquisa)/Projeto E-6/110.324/2007, and Confederação Nacional do Comércio. Drs. Ventura, Coutinho and Figueira were supported by grants from CNPq. Dr. Neylan was partially supported by the NIMH Grants: MH057157 \& MH73978.

\section{References}

1. Foa E. Psychosocial therapy for posttraumatic stress disorder. J Clin Psychiatr. 2006;67(Suppl 2):40-5.

2. Foa EB, Keane TM, Friedman MJ, editors. Effective treatments for PTSD. Pratice guidelines from the international society for traumatic stress studies. 2nd ed. New York: The Guilford Press; 2009.

3. Hofmann SG, Smits JAJ. Cognitive behavioral therapy for adult anxiety disorders: a meta-analysis of randomized placebo-controlled trials. J Clin Psychiatry. 2008;64:4.

4. Mendes DD, Mello MF, Ventura P, Passarela M, Mari J. A systematic review on the effectiveness of cognitive behavioral therapy for posttraumatic stress disorder. Int J Psychiatry Med. 2008;38(3):241-59.

5. Passarela CD, Mendes DD, Mari JD. A systematic review to study the efficacy of cognitive behavioral therapy for sexually abused children and adolescents with posttraumatic stress disorder. Rev Psiq Clín. 2010;37(2):63-8.

6. Bisson J. Post-traumatic stress disorder. Occup Med. 2007;57(6):399-403.

7. Marmar CR. Mental health impact of Afghanistan and Iraq deployment: meeting the challenge of a new generation of veterans. Depress Anxiety. 2009;26:493-7.

8. Norte CE, Souza GGL, Pedrozo AL, Mendonça-de-Souza ACF, Figueira I, Volchan E, et al. Impact of cognitive-behavior therapy on resilience-related neurobiological factors. Rev Psiq Clín. 2011;38(1):43-5.

9. Moras K. The value of neuroscience strategies to accelerate progress in psychological treatment research. Can J Psychiatry. 2006;51(13):81022 .

10. Schottenbauer MA, Glass DB, Arnkoff, DB, Tendick AV, Gray SH. Nonresponse and dropout rates in outcome studies on PTSD: review and methodological considerations. Psychiatry. 2008;71(2):134-68.

11. Beauchaine TP, Neuhaus E, Brenner SL, Gatzke-Kopp L. Ten good reasons to consider biological processes in prevention and intervention research. Dev Psychopathol. 2008;20:745-74.

12. Pincus HA, Henderson B, Blackwood D, Dial T. Trends in research in two general psychiatric journals in 1969-1990: research on research. Am J Psychiatry. 1993;150:135-42.

13. Smyth JM, Hockemeyer JR, Tulloch H. Expressive writing and post-traumatic stress disorder: effects on trauma symptoms, mood states, and cortisol reactivity. Brit J Health Psych. 2008;13:85-93.

14. Boudewyns PA, Hyer L. Physiological response to combat memories and preliminary treatment outcome in Vietnam veteran PTSD patients treated with direct therapeutic exposure. Behav Ther. 1990;21:63-87.

15. Pitman RK, Orr SP, Altman B, Longpre RE, Poiré RE, Macklin ML, et al. Emotional processing and outcome of imaginal flooding therapy in Vietnam veterans with chronic posttraumatic stress disorder. Compr Psychiatry. 1996;37(6):409-18.

16. Blanchard EB, Hickling EJ, Veazey CH, Buckley TC, Freidenberg BM, Walsh GD, et al. Treatment-related changes in cardiovascular reactivity to trauma cues in motor vehicle accident-related PTSD. Behav Ther. 2002;33:417-26.

17. Frueh BC, Turner SM, Beidel DC, Mirabella RF, Jones WJ. Trauma management therapy: a preliminary evaluation of a multicomponent behavioral treatment for chronic combat-related PTSD. Behav Res Ther. 1996;34(7):533-43.

18. Cooper NA, Clum GA. Imaginal flooding as a supplementary treatment for PTSD in combat veterans: a controlled study. Behav Ther. 1989;20:381-91.

19. Fecteau G, Nicki R. Cognitive behavioural treatment of post traumatic stress disorder after motor vehicle accident. Behav Cogn Psychother. 1999;27:201-14. 
20. Hinton DE, Hofmann SG, Pollack MH, Otto MW. Mechanisms of efficacy of CBT for Cambodian refugees with PTSD: improvement in emotion regulation and orthostatic blood pressure response. CNS Neurosci Ther. 2009;15:255-63.

21. Farrow TFD, Hunter MD, Wilkinson ID, Gouneea C, Fawbert D, Smith $\mathrm{R}$, et al. Quantifiable change in functional brain response to empathic and forgivability judgments with resolution of posttraumatic stress disorder. Psychiatry Res. 2005; 140:45-53.

22. Yehuda R, Bierer LM, Sarapas C, Makotkine I, Andrew R, Seckl JR. Cortisol metabolic predictors of response to psychotherapy for symptoms of PTSD in survivors of the World Trade Center attacks on September 11, 2001. Psychoneuroendocrinology. 2009;34(9):1304-13.

23. Bryant RA, Felmingham K, Kemp A, Das P, Hughes G, Peduto A, et al. Amygdala and ventral anterior cingulate activation predicts treatment response to cognitive behaviour therapy for post-traumatic stress disorder. Psychol Med. 2008;38:555-61.

24. Bryant RA, Felmingham K, Whitford TJ, Kemp A, Hughes G, Peduto A, et al. Rostral anterior cingulate volume predicts treatment response to cognitive-behavioural therapy for posttraumatic stress disorder. J Psychiatry Neurosci. 2008;33(2):142-6.
25. Davidson JR, Hughes D, Blazer DG, George LK. Posttraumatic stress in the community: an epidemiological study. Psychol Med. 1991;21:713-21.

26. Pole N. The psychophysiology of posttraumatic stress disorder: a meta-analysis. Psychol Bull. 2007;133(5):725-46.

27. Yehuda R. Current status of cortisol findings in post-traumatic stress disorder. Psychiatr Clin North Am. 2002;25:341-36.

28. Porto P, Oliveira L, Mari J, Volchan E, Figueira I, Ventura P. Does Cognitive Behavioral Therapy change the brain? A systematic review of neuroimage in anxiety disorders. J Neuropsychiatry Clin Neurosci. 2009;21:114-25.

29. Yehuda R, Bierer LM, Andrew R, Schmeidler J, Seckl JR. Enduring effects of severe developmental adversity, including nutritional deprivation, on cortisol metabolism in aging Holocaust survivors. J Psychiatr Res. 2009;43:877-83.

30. Kato N, Kawata M, Pitman RK, editors. PTSD brain mechanisms and clinical implications. Tokyo: Springer-Verlag; 2006.

31. Rauch SL, Shin LM, Phelps EA. Neurocircuitry models of posttraumatic stress disorder and extinction: human neuroimaging research - past, present, and future. Biol Psychiatry. 2006;60:376-82.

32. Tashiro T, Mortensen L. Translational research how can social psychology improve psychotherapy. Am Psychol. 2006;61(9):959-66. 